\title{
Outcome of small minimal incision technique \& posteriorly based periosteal flap with subcutaneous closure in cochlear implant surgery
}

\begin{abstract}
Background: Although cortical mastoidectomy and posterior tympanotomy has not changed for more than 40 years, the major changes are in the skin flap incision and implant technique in CI surgery. Regarding the incision technique the smaller the incision with less soft tissue manipulation the best. Post-operative healing and scar result also small incision have adequate blood supply and venous drainage, graft has good exposure and coverage of the PP field. There are different types of incisions and flaps which are used by different surgeons around the world for cochlear implant surgery. In this study 3 types of incisions and flaps were used, Small incision for cochlear implant surgery reduce the morbidity and increase parent satisfaction as compared with wider access operation incisions also will prevent the scalp flap complication, this is achieved by good flab design that should have adequate blood supply and venous drainage, enough field exposure and coverage.
\end{abstract}

Methods: This is retrospective study for 145 child age ranges between (1-5)years old underwent cochlear implant surgery with deferent companies (AB, cochlear, med el) in Al-Yarmouk Teaching Hospital/ENT department from 2014- July.2018. 3 types of incisions and flaps were used, Slight curve line post auricle incision (Small hair line post-auricle incision), Lazy S incision, Small post-auricle with superior extension, was made with posterior flap elevation was used as an axis to the mastoid cavity and the wheel for the implant device, with subcutaneous closure and without skin closure.

Result: It's found that there is early healing, no major flap complication by using Slight curve line post auricle incision (Small hair line post-auricle incision), no skin stitches are required, end with minimum or no scar, minimum time consuming and easy follow-up for the children post-operatively.

Keywords: surgery, auricle incision, major flap, skin stitches, soft tissue
Volume II Issue 4 - 2019

\author{
Bahaa Mohsin Al-Anbari,' Adnan Qahtan \\ Khalaf,' Feryal Shakir Taher ${ }^{3}$ \\ 'CABS (ORL HNS) Consultants Otolaryngologist, Iraq \\ ${ }^{2}$ F.IC.M.S. Otolaryngologist, laser specialist, Iraq \\ ${ }^{3}$ F.IC.M.S. Consultants Otolaryngologist, Iraq
}

Correspondence: Adnan Qahtan Khalaf, F.IC.M.S. Otolaryngologist, laser specialist, AL-Yarmouk Teaching Hospital, Baghdad, Iraq, Email adnan_khtan@yahoo.com

Received: June 27, 2019 | Published: July 31, 2019

\section{Introduction}

Failure of Skin flap is uncommon complication of cochlear implant surgery, the small incision cochlear implant surgery reduce morbidity ${ }^{1,2}$ and improves patient and parent satisfaction ${ }^{3}$ as compared with wider access operation. Scalp flap complication can be prevented by good flap design, which should have adequate blood supply enough field exposure and coverage. Also, excessive manipulations may lead to postoperative complication, such as devascularization, which lead to seromas and hematoma formation as well as flap necrosis and infection. ${ }^{4-6}$ To our knowledge the blood supply to the field are involves 3 branches mainly as shown in Figure 1 of the external carotid artery include the occipital, post auricular and superficial temporal artery. venous drainage parallels with the arterial supply and gravity which facilitates this drainage if the incision impede the blood supply or cross electrode and the receiver have the chance to break and may lead to fail short after the operation. Most different incision which are recommended for CI, were reviewed the $\mathrm{J}$ shaped straight ${ }^{5}$ lazys. ${ }^{6}$ Inverted u shape hockey sticks ${ }^{7}$ anterior based c shape and end metal incisions as shown in Figure 2.

Complications of soft tissue were divided into minor and major complication. Minor complications which not threaten the device survival and could be managed conservatively such as minor seromas, hematoma and sacrificial soft tissue infections. Major complication Include those that required operative invasive intervention due to threatened device survival this include large seromas, loss of device fixation, device extrusion, and soft tissue infection. Simple case of skin redness over the site of magnet. ${ }^{8}$

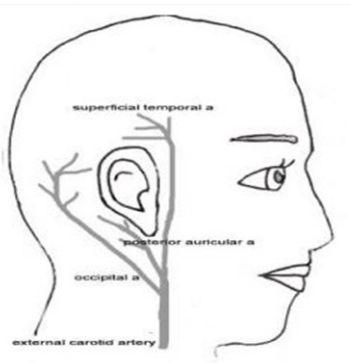

Figure I Vascular supply to the post auricular area.

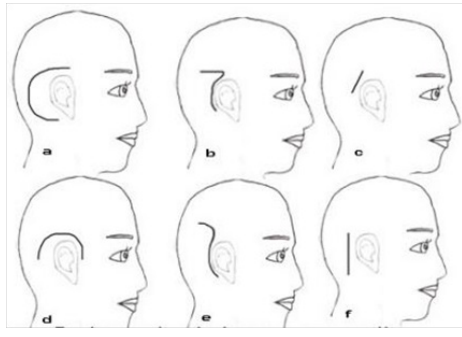

Figure 2 types of post auricular incision. 


\section{Materials and method}

145 child age range between (1-5)years old, undergoing cochlear implant surgery in Al-Yarmouk Teaching Hospital/ENT department from 2014- July.2018.

Slight curve line post auricle incision $(1-4 \mathrm{~cm})$ as shown in Figures $3 \& 4$ was made and posterior flap elevation was used as an axis to the mastoid cavity as shown in Figure 5 (posterior flap elevation) in most of the cases and other cases Lazy S incision, Small post-auricle with superior extension incision was done 3 types of flap was done in this study as shown in the in Table $1 \& 2$ the wheel for the implant device was done as shown in Figure 6 (drilling of the mastoid cavity, posterior tympanotomy and wheel for the implant device) with subcutaneous closure, without using skin stitches after finishing the implantation as shown in Figure 7 (subcutaneous closure and without skin closure). This type of incision prevents cutting of the main trunk of feeding vessels. Posterior based periosteal flap was done $1 \mathrm{~cm}$ behind and underneath the skin incision to get good coverage of the receiver, the electrodes and the incision line.

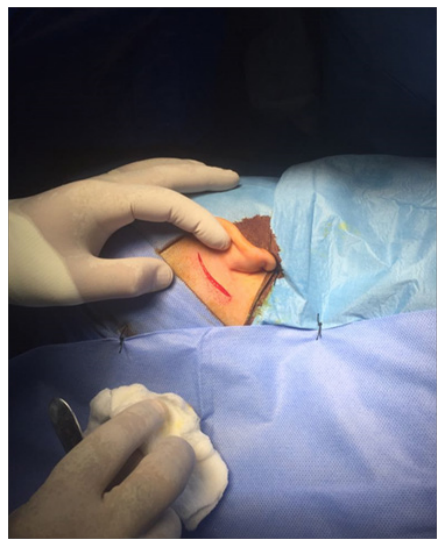

Figure 3 Post auricle incision.

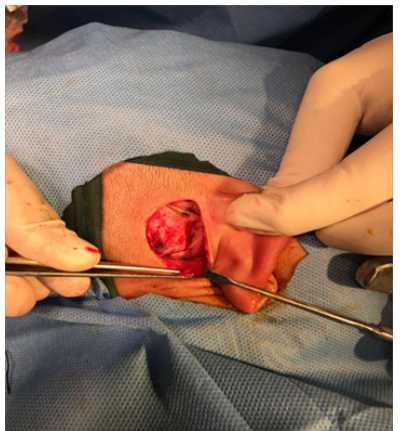

Figure 4 line of posterior flap.

Through the that incision good exposure, simple mastoidectomy and proper wheel done for the receiver by drilling under periosteum, after introduction of the implant device, accurate closure of the periosteum would be performed with minimum tension using absorbable sutures. ${ }^{9-12}$ Skin closure in subcuticular layer. Light dressing keeps the skin flap and prevent hematoma collection. All patients received intravenous antibiotics prophylaxes at the time of surgery, followed by 10days course of oral antibiotics postoperative.
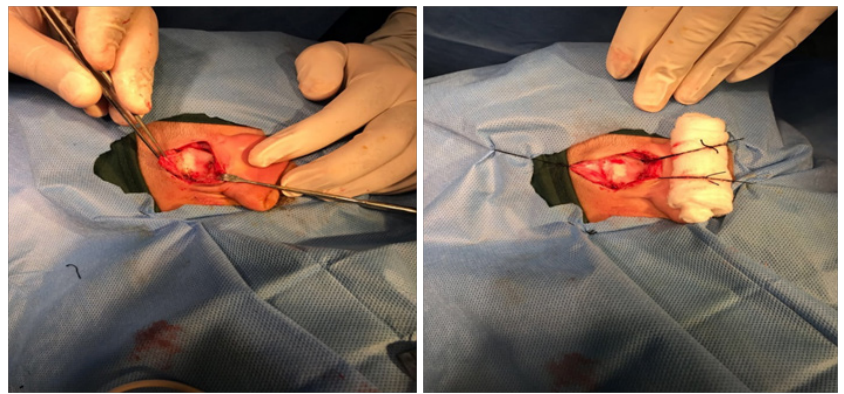

Figure 5 (posterior flap elevation).

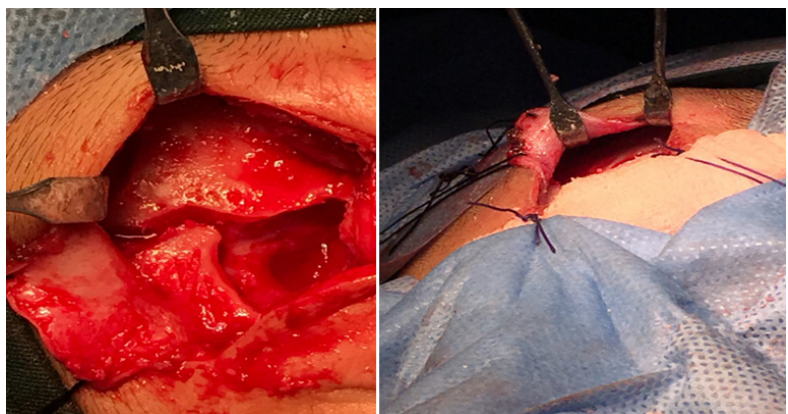

Figure 6 Drilling of the mastoid cavity, posterior tympanotomy and wheel for the implant device.
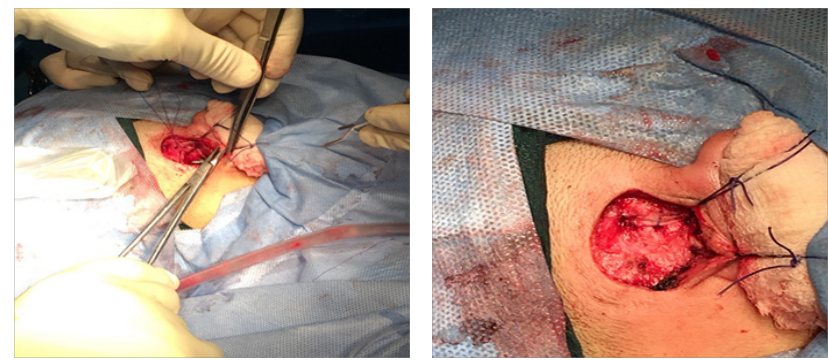

Figure 7 Closuring of the periosteum flap after cochlear implant.

\section{Result}

In all the cases, no major cutaneous infection or failure happened. All the patient family was satisfied about cosmetic outcome of new incision. Subcutaneous fluid collection or other minor complication did not occur as shown in Figures $8 \& 9$ It's found that there is early healing, no major flap complication by using Slight curve line post auricle incision (Small hair line post-auricle incision), no skin stitches are required, end with minimum or no scar, minimum time consuming and easy follow-up for the children post-operatively. Total number of Cochlear implant patient 145 (Table 1\&2).

Table I Type of incisions

\begin{tabular}{ll}
\hline Type of incision & No. \\
\hline Lazy S incision & 5 \\
Small post-auricle with superior extension & 20 \\
Small hair line post-auricle incision & 120
\end{tabular}


Table 2 Type of flaps

\begin{tabular}{ll}
\hline Type of flap & No. \\
\hline Posterior based flap & 90 \\
Superior based flap & 20 \\
Anterior based flap & 35 \\
\hline
\end{tabular}
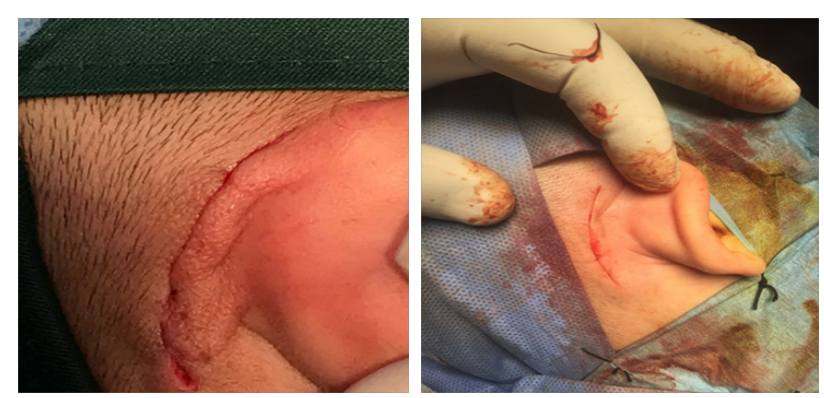

Figure 8 subcutaneous closure and without skin closure.
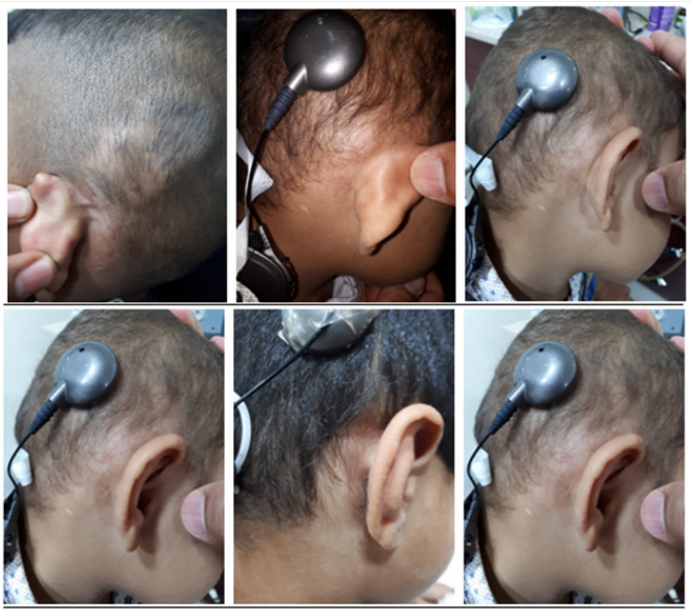

Figure 9 Shows post-operative wound healing after cochlear implants surgery.

\section{Discussion}

Minimal incision is safe and effective approach for cochlear implantation. Slight curve incision has been used to obtain a less disturbed amount of soft tissue blood supply, decrease the dead space, reducing the time of the operation and the post portative rate of infection. Regarding the posterior based flap has been used to achieve complete periosteum cover to the device, the site of incision is away from the device, minimize the rate of infection, no overlapping between the skin incision and the underlying periosteum closure. Minimal access incision has been shown to be a safe and effective approach for pediatric CI candidates. ${ }^{13-16} \mathrm{O}$ 'Donoghue and Nikolopoulos (2002) described a minimal incision no greater that $3 \mathrm{~cm}$, with creating a pocket in the subperiosteal for fixation of the device. 120 pediatric patients implanted via this approach, there were only one case of erosion of the skin in the series, with no other complication had occurred. ${ }^{13}$

Advantages of the minimal access approach technique include minimum edema; reduce dead space, and vascular compromise that may have an effect on postoperative infection rates. The lack of edema and decrease in pain allows for earlier mapping and activation of the device. Fixation of the device can be achieved by many methods including soft-tissue pocket tightly or by fixation technique, such as suture tie-down. Stratigouleas et al. (2006) described a subperiosteal pocket that was created for device positioning, without any device fixation.

In minimal access incision, no tie-down approach was used, instead, the device held in place with a tight subperiosteal envelope. Although it is possible loss of fixation by infection causing bone loss or disrupting the tie-down suture by trauma, mobility of the device may lead to the development of seromas and/or infection. Therefore we believe that a tie-down procedure should be done ideally be performed in all cases, even those with thick cortical bone, ${ }^{16}$ this may lead to lower the rate of soft tissue complications.

There is advantages and disadvantages for different incisions and flaps elevation techniques. The advantage of classic anteriorly based "C-shaped" was providing complete coverage of the device without crossing the implant, but this design of flap has poor gravity based venous drainage and may lead to edema. ${ }^{13}$ The "J-shaped" flaps and Inverted "U-shaped" and have the advantage of blood supply and drainage of the venous system but the incision line, crosses the electrode. ${ }^{13}$ "lazy S" and "straight" incisions have limitations due to crossing the device, ${ }^{12}$ and all them have limitations in exposure and application of the device. ${ }^{13,16}$ The classic " $\mathrm{C}$ " incision has the advantage of a good blood supply but irregular and poor cosmetic outcome. ${ }^{16}$ The "new" incision which consider as modification of is "Hockey stick" has smaller backward extension, so has less visible suture line and as anteriorly based periosteal flap secure coverage over the device, failure rate of skin flap is lower. The superiority of the "new" flap over the "classic" and others was intact complete blood supply with good soft tissue coverage over the device and good cosmetic outcome.

Complications such as scalp flap deficits, although very rare, but still can occur. Executions to prevent the known mistakes may reduce the risk of flap complications by developing the flap designs. Table 1 compares the flap failures of different incisions. This "new" design is easy to perform while provides an appropriate vascular supply, a good field of exposure and coverage; without cosmetic problems.

\section{Acknowledgments}

None.

\section{Conflict of interest}

We declare there is no financial interest or any conflict of interest.

\section{Funding}

None.

\section{References}

1. Gibson WP, Harrison HC, Prowse C. A new incision for placement of cochlear implants. J Laryngol Otol. 1995;109(9):821-825.

2. O Donoghue GM, Nikolopoulos TP. Minimal access surgery for pediatric cochlear implantation. Otol Neurotol. 2002;23(6):891-894.

3. Eshraghi A, Balkany TJ, Telischi FF, et al. Minimal incision technique for cochlear implantation. Annual meeting of the American Academy of Otolaryngology-Head \& Neck Surgery, 2002. p. 22-25. 
4. Bhatia K, Gibbin KP, Nikolopoulos TP, et al. Surgical complication and their management in a series of 300 consecutive pediatric cochlear implantations. Otol Neurotol. 2004;25:730-739.

5. Arnoldner C, Baumgartner WD, Gstoettner W, et al. Surgical considerations in cochlear implantation in children and adults: a review of 342 cases in Vienna. Acta Otolaryngol. 2005;125(3):228-234.

6. Cunningham CD, Slattery WH, Luxford WM. Postoperative infection in cochlear implant patients. Otolaryngol Head Neck Surg. 2004;131(1):109_ 114.

7. Gibson WP, Harrison HC, Prowse C. A new incision for placement of cochlear implants. J Laryngol Otol. 1995;109(9):821-825.

8. Ray J, Gibson W, Sanli H. Surgical complications of 844 consecutive cochlear implantations and observations on large versus small incisions. Cochlear Implants Int. 2004;5(3):87-95.

9. Slavutsky V, Nicenboim L. Preliminary results in cochlear implant surgery without antromastoidectomy and with atraumatic electrode insertion: the endomeatal approach. Eur Arch Otorhinolaryngol. 2009;266(4):481-488.

10. Glasscock ME. Expenses keep cochlear implants out of reach for millions of individuals with profound hearing loss in poor and emerging countries. Otol Neurotol. 2011;32(5):893-894.
11. Ajalloueyan M, Amirsalari S, Radfar Sh. Flap outcome using "c" shaped and "new" incisions in pediatric cochlear implantation. Iran Red Crescent Med J. 2012;14(4):218-221.

12. James AL, Daniel SJ, Richmond L, et al. Skin breakdown over cochlear implants: prevention of a magnet site complication. J Otalaryngol. 2004;33(3):151-154.

13. Stratigouleas ED, Perry BP, King SM, et al. Complication rate of minimally invasive cochlear implantation. Otolayngol Head Neck Surg. 2006;135(3):383-386

14. James AL. Papsin BC device fixation and small incision access for pediatric cochlear implants. Int $J$ Pediatr otorhinolaryngol. 2004;68(8):1017-1022.

15. James AL, Papsin BC. Cochlear implants, surgery at 12 months of ages or younger. Laryngoscope. 2014;114(12):2191-1294.

16. O’Donoghue GM, Nikolopoulos TP. Minimal access surgery for pediatric cochlear implantation. Otol Neurotol. 2002;23(6):891-894. 